\title{
ELECCIONES EN HESSE, \\ VOTO DE CENSURA CONSTRUCTIVO \\ Y ELECCIONES EN BAVIERA
}

Las elecciones en el Estado de Hesse agudizaron la crisis política en la República Federal Alemana. De nuevo se generaba aquí la situación de ambigüedad e indecisión que caracterizó a los resultados electorales en Hamburgo, impidiendo la formación de una mayoría parlamentaria y haciendo depender el gobierno minoritario de la SPD de la difícil aquiescencia de los «verdes» o ecologistas. Estos últimos eran los únicos que conseguían mejorar espectacularmente los resultados abtenidos en 1978 , pasando del 2 por 100 al 8 por 100 de los votos. Pero lo más significativo era, sin lugar a dudas, el vertiginoso descenso de los liberales, quienes eran nuevamente abocados a una presencia extraparlamentaria, casi meramentè testimonial, con el 3,1 por 100 de sufragios. El electorado premiaba de este modo negativamente la desigual táctica del líder nacional de la FDP, Genscher, quien, ante la progresiva pérdida de votos de la coalición socialdemócrata-liberal, no dudó en cambiar ésta de signo, buscando la alianza con la CDU. Por su parte, los «verdes» afianzaban su posición como tercera fuerza política de la República Federal Alemana, confirmando su profunda y creciente implantación social.

La inestabilidad extrema de la situación condujo a la disolución de la coalición SPD-FDP, que gobernaba desde 1969, y su sustitución, pese al test negativo de Hesse, por una nueva mayoría parlamentaria CDU-FDP. De este modo, Helmut Kohl se convertía con 256 votos (siete más de la mayoría absoluta prescrita por el artículo 67 de la Ley Fundamental alemana), a través del procedimiento del voto de censura constructivo, en el sexto canciller de la República Federal alemana: era el 1 de octubre de 1982. Ante las dudas sobre la legitimación del cambio de gobierno, efectuado sin pasar por las urnas, y ante la precaria situación política por la que atraviesa la República Federal, Kohl aseguró en el debate previo a la moción de censura la convocatoria de elecciones generales para el día 6 de marzo.

Ahora bien, hasta qué punto le va a ser posible al nuevo Gobierno mantener esta fecha, y aún la promesa de nuevas elecciones, no resulta fácil de predecir. Frente a la urgencia de un gobierno parlamentariamente fuerte, amparado por un respaldo social amplio, se alzan graves dificultades jurídico-constitucionales.

La única posibilidad de convocar elecciones anticipadas pasa por una moción de censura manipulada, propiciada por el propio gobierno Kohl (lo que obligaría a los diputados democristianos a ausentarse durante la votación), que permitiese al presidente Carstens la disolución del Bundestag sobre la base legal del artículo 68 de la Grundgesetz. El artículo 68 prevé la disolución del Bundestag por el Bundespräsident en el plazo de veintiún días caso de no triunfar el canciller federal ante la Cámara 
en la correspondiente moción de confianza. Todo ello se produciría paradójicamente después de ser aprobado el presupuesto del Gabinete Kohl para 1983, es decir, después de una expresa manifestación de confianza por parte de la Cámara, lo que no habla precisamente a favor de la coherencia del método, ni tampoco de los resultados.

Es una más que interesente ironía de la historia el hecho de que, merced al artículo 68, el presidente Carstens se encontraría en una situación muy cercana a una decisión de tipo presidencialista, en un curioso paralelismo histórico con el famoso artículo 48 de la Constitución de Weimar: justamente el precepto que motivó la agonía de la República de Weimar, y ante la que la propia Grundgesetz de 1949 quiso significar una respuesta constitucional definitiva. Por todo ello es probable que, aún en el supuesto de llegar los partidos a acordar la moción de censura manipulada, el Tribunal Constitucional de Karlsruhe no toleraría una ficción política que $\tan$ directamente se opone al espíritu e intención de la norma fundamental alemana.

La otra alternativa no es de menor complejidad, además de políticamente más arriesgada. Se trataría de una reforma constitucional que introdujese el derecho de autodisolución del Bundestag. Esta es un arma de acerado doble filo, pues, si, por una parte, daría paso a la celebración de nuevas elecciones, hoy absolutamente necesarias para clarificar la situación política, por otra, supuesta la dificultad de configurar mayorías capaces de gobernar, introduce la posibilidad de permanentes crisis parlamentarias que podrían abocar al sistema parlamentario a posiciones no menos agónicas que las de principios de los años treinta. En este contexto, los resultados de las elecciones de Baviera (ligero descenso y aumento respectivamente de la SPD y la CDU, claro ascenso de los verdes) no hicieron sino afianzar la ambigüedad de la situación, planteando de nuevo con toda virulencia la pregunta clave: ¿cómo conseguir integrar ese casi 10 por 100 de la población (ecologista, alternativos, pacifistas, radicales) que se sitúa, hoy por hoy, fuera y frente al régimen parlamentario?, y, sobre todo, ¿cómo lograr renovar o transformar, manteniendo los logros del parlamentarismo, aquella fórmula de legitimación que para Rudolf Smend constituía el núcleo integratorio básico de la democracia liberal, a saber, el mito del progreso?

Dejando de lado los profetismos catastrofistas que alimentan la oscura palabra «Unregierbarkeit» (ingobernabilidad del país), la República Federal de Alemania acabará optando probablemente por volver a aplicar la fórmula ya ensayada con la «oposición extraparlamentaria» en el 68: políticamente, una gran coalición CDUSPD; socialmente, la progresiva integración (y lo que ello implica de superación de la cultura tecnológica dominante) del movimiento ecologista.

\section{ELECCIONES EN HESSE}

\begin{tabular}{|c|c|c|}
\hline \multirow{2}{*}{$\begin{array}{c}\text { ELECCIONES } \\
\text { (En porcentajes) }\end{array}$} & \multicolumn{2}{|c|}{ HESSE } \\
\hline & 1978 & 1982 \\
\hline $\begin{array}{llllll} & \text { SPD } & \ldots & \ldots & \ldots & \ldots\end{array}$ & 44,3 & 42,8 \\
\hline $\begin{array}{llllll}\text { CDU } & \ldots & \ldots & \ldots & \ldots\end{array}$ & 46,0 & 45,6 \\
\hline $\begin{array}{lllll}\text { FDP } & \ldots & \ldots & \ldots & \ldots\end{array}$ & 6,6 & 3,1 \\
\hline $\begin{array}{lllll}\text { Grünen } & \ldots & \ldots & \ldots\end{array}$ & 2,0 & 8,0 \\
\hline
\end{tabular}

José María Beneyto 